\title{
Contact statuses distributions of flat forming tool profile effect in incremental forming process by finite element analysis
}

\author{
Khalil Ibrahim Abass* \\ AL-Mustansiriya University, Engineering Collage, Mechanical Engineering Department, Baghdad, Iraq.
}

\begin{abstract}
Single Point Incremental Forming process (SPIF) is a modern forming technique of sheet material. Principles of the process are based on manufacturing by layers-two dimensions layers with step size depth of the tool path. The movement of a hemispherical forming tool is using Computer Numerical Control (CNC) machine to produce the profile of the final product. The description of the process is more complicated by highly nonlinear boundary conditions. The paper presents a study of the effect of the flat forming tool profile through FEA on SPIF that permits the modelling of complex product geometries, material behaviour and boundary conditions. The results showed that the model of simulation can predict the behaviour of contact tool-blank, and the accuracy of product.
\end{abstract}

\section{Introduction}

Single Point Incremental Forming (SPIF) is a flexible sheet metal forming process with potential for small production and for rapid forming tools. Numerical Control (NC) milling machine is used for execution of the product and the forming tool path is programmed by Computer Aided Manufacturing (CAM) software. The geometry of the product is included into two-dimensional (2D) layers and the designed product profile is deformed in multilayer movement of a hemispherical forming tool [1] (Fig. 1, [2]).

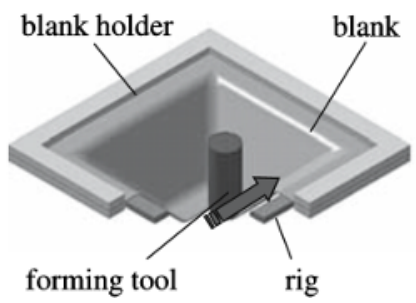

Fig. 1. SPIF technology principle [2].

The deformation of the sheet metal occurs only in the processing zone and is a combination of shearing and stretching processes. Finally, the thinning occurs during SPIF process and the wall thickness along the product section is lower than the blank thickness [4].

* Corresponding author: Khalil1969a@yahoo.com 
Main parameters of the process that influence the quality and the accuracy of the formed blank are: spindle speed $(\omega)$, feed rate $(v)$, tool vertical step $(\Delta z)$ and tool diameter $\left(D_{p}\right)[3]$.

Advantages of SPIF process: highly flexible process, low hardware costs, enabling production of complex shapes, shorter time-to-market. SPIF process would be useful for prototyping and small-batches production for automobile, biomedical and aerospace industries [5]. Disadvantages of SPIF process: long forming time when compared to deep drawing process, small-lot production, low accuracy of the geometry, high springback, in bending edges and convex radius areas [6].

The forming tool radius effect on accuracy and ability of SPIF deforming process is studied with wide ranges (between 2-25 mm) of radiuses of the round head. The interaction between the tool step size and sheet metal thickness was researched [7]. They concluded that the maximum forming wall angle is influenced by this interaction.

The effect of forming tool radius, step size, and speed of forming on the formability were studied [8]. The formability was observed through a surface response method called central composite rotational design. The authors concluded that the forming tool radius and the step size have an important effect on the formability, and it can be decreased or increased depending on the step size.

Five hemispherical forming tools with 4-25 mm radius to deform aluminum AA1050H111 were used in the experiment [9]. As a result, the stability effect is not significant to ensure localization, and the failure mechanism will change to promote fracture with suppression of necking when using the small forming tool.

A range of the forming tool diameter between $5-10 \mathrm{~mm}$ was selected, to predict the effect with low rotating speed by FEM [10]. While, selected a range between 4-6 mm forming tool diameter to study the forming tool radius effect on polymer products [11].

Two types of the forming tools, flat and hemispherical heads were studied [12]. The paper showed that the flat head forming tool required lower forming force, and can give a better accuracy of the product profile and formability than the others. A lot of researchers didn't take into account the effect of the forming tool radius and selected one value of the radius, depending upon previous papers $[13,14,15]$, who selected a $5 \mathrm{~mm}$ forming tool radius, or $[16,17]$ who selected a $15 \mathrm{~mm}$ forming tool radius.

This research focuses on using a flat forming tool profiles and on evaluating the product profile, thickness and strain distribution, compared to other profiles. A new type of evaluation was used - contact status distributions by Auto CAD application and FEA method to observe the behaviour of the entire blank surface and the forming tool surface.

\section{FE simulation model development}

The FE simulation model was undertaken to represent the metal forming process. The input stage involves physical SPIF model geometric, material properties and boundary conditions. The processing stage takes into account the analysis of FEM and evaluated shape, for the failure product or success. The output stage includes the final product for calculation and conclusions. FEM analysis application program, ANSYS 11 of linear and nonlinear general purpose, is used. Script files of the commands were used to improve specific tedious data response tasks during pre-processing and post-processing, by using the FEM in a system for an integrated engineering methodology to sheet metal forming.

The FE simulation model of SPIF process was developed. The model contains the effect of direct and indirect contact between the tool set - blank, in addition to the elastic-plastic behavior of the blank material. To develop the FE model, the effect of flat forming tools was studied with constant values (dimension and materials) of fixture (die and blank holder) and blank, as shown in Tables 1 and 2. 
Symmetric components to model blanks are used, that are rotated about an axis symmetrically. The analysis of the two dimensional sector of the deformed blank is carried out in order to evaluate the complete shape of the product. A pure Aluminum AA1050 as a workpiece was used, and the mechanical properties of the material are shown in Table 2.

Table 1. Dimensions and variables of SPIF tools.

\begin{tabular}{|l|ll|}
\hline \multicolumn{1}{|c|}{ Variable } & \multicolumn{2}{c|}{ Value } \\
\hline Dia. of active forming tool, $\mathrm{D}_{\mathrm{p}}$ & $\emptyset 8-16$ & $(\mathrm{~mm})$ \\
\hline Radius of Die, $\mathrm{R}_{\mathrm{d}}$ & 5 & $(\mathrm{~mm})$ \\
\hline Radius of forming tool edge, $\mathrm{R}_{\mathrm{P}}$ & 4 & $(\mathrm{~mm})$ \\
\hline Dia. of blank, $\mathrm{D}_{\mathrm{b}}$ & $\emptyset 220$ & $(\mathrm{~mm})$ \\
\hline Blank thickness, $\mathrm{t}$ & 0.9 & $(\mathrm{~mm})$ \\
\hline Dia. of die hole, $\mathrm{D}_{\mathrm{d}}$ & $\varnothing 180$ & $(\mathrm{~mm})$ \\
\hline Step size, $x$ and y directions & 0.1 & $(\mathrm{~mm})$ \\
\hline Friction coefficient, $\mu$ & 0.05 & \\
\hline Dim. of start tool position & $\emptyset 76-80$ & $(\mathrm{~mm})$ \\
\hline
\end{tabular}

Table 2. Material properties of the blank.

\begin{tabular}{|l|c|}
\hline \multicolumn{2}{|c|}{ Material, $\mathrm{Al}(\mathrm{AA} 1050)$} \\
\hline Yield stress, $\boldsymbol{\sigma}_{\boldsymbol{y}}, \mathrm{MPa}$ & 80 \\
\hline Young's modulus, E, GPa & 75 \\
\hline Poisson's ratio, $\mathbf{v}$ & 0.3 \\
\hline Density, $\boldsymbol{\rho}, \mathrm{g} / \mathrm{m}^{3}$ & 2700 \\
\hline Tangent modules, $\mathbf{E} \boldsymbol{\tau}, \mathrm{Pa}$ & 0.5 \\
\hline
\end{tabular}

The elements PLANE42-2D and V15C0106-2D were chosen to represent the forming tool set (fixture, die and forming tool) and blank respectively. Both elements have the nodal directions $\mathrm{x}$ and $\mathrm{y}$ translation. For the blank meshing is used a quadrilateral mapped mesh.

The boundary conditions include loading, displacement, friction coefficient and (direct and indirect) contact and are represented as following (Fig. 4):

1. The constraint of the die was held fixed in two directions $x$ and $y, N 1$ and N2, by nodal;

2. The constraint of the blank holder was as to allow in one direction y movement, N3 and N4;

3. The constraint of the blank was along the centerline, N5 with zero displacement in y direction;

4. Movement of forming tool was identified in a profile with constant feed rate (Fig. 4);

5. The specific incremental loads and load steps in two directions are applied.

The pair Point-to-Surface contact elements CONTAC169 and CONTAC171-2D were used to represent the contact conditions, like a Rigid-to-flexible contact between the tool set and the blank respectively. The contact surfaces, a real constant set were used for each interface. The convergence criteria and non-linear analysis are applied. The convergence tolerance was based on minimization of the residual force.

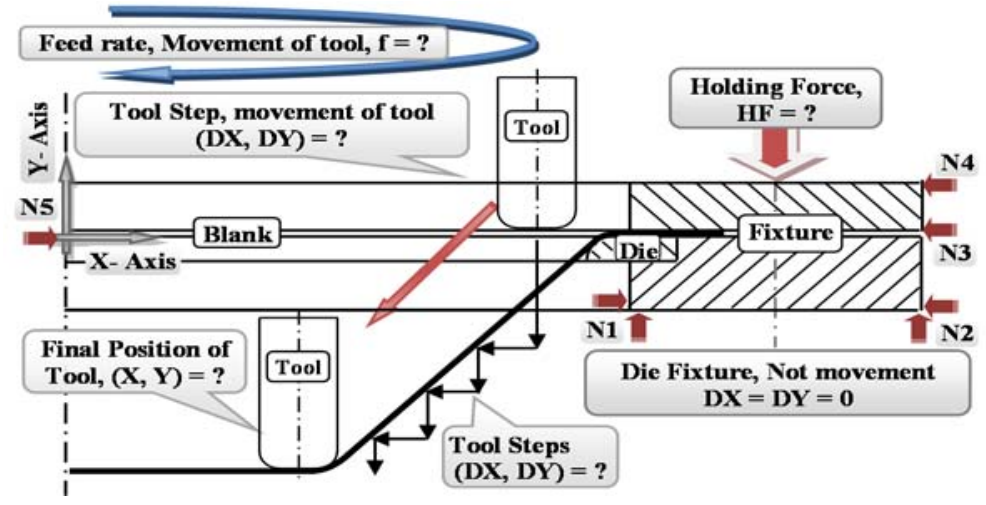

Fig. 4. SPIF process boundary conditions.

\section{Results and discussion}

The results evaluation included the following: a) forming tool movement examination, resulting from Auto $\mathrm{CAD}$ application; b) analysis of the simulated product profile based on 
the forming tool movement; c) thickness and strain distributions comparison; d) contact statuses distributions assessment at the interface between tool and workpiece.

The contact statuses distributions assessment at the interface between tool and workpiece evaluation is representing in Fig. 5. In this case, the forming tool moves at a $45^{\circ}$ at three stages $(2 \times 2,20 \times 20,40 \times 40) \mathrm{mm}$ in $\mathrm{x}$ and $\mathrm{y}$ directions.

The contact in case of the spherical profile case begins with a point, until the shape of the blank surface becomes identical to the forming tool edge profile shape, which occurs gradually, with increasing the depth, more precisely at final stroke. The highest value for the contact distance was $2.64 \mathrm{~mm}$, around the edge.

In case of the flat forming tool, the observation was that at the beginning of the stroke, the contact takes the form of a line, and as the depth increases, it takes the form of the edge of the forming tool. At the end of the stroke, the maximum contact distance was $10.64 \mathrm{~mm}$. Another observation was that in all the cases, the contact area increases as depth of deformation increases as follows: $0 \mathrm{~mm}$ to $2.64 \mathrm{~mm}, 2 \mathrm{~mm}$ to $4.64 \mathrm{~mm}, 4 \mathrm{~mm}$ to $6.64 \mathrm{~mm}$, $6 \mathrm{~mm}$ to $8.64 \mathrm{~mm}, 8 \mathrm{~mm}$ to $10.64 \mathrm{~mm}$. Also, the shape of the product end edge is going to emulate the shape of the edge of the forming tool profile.
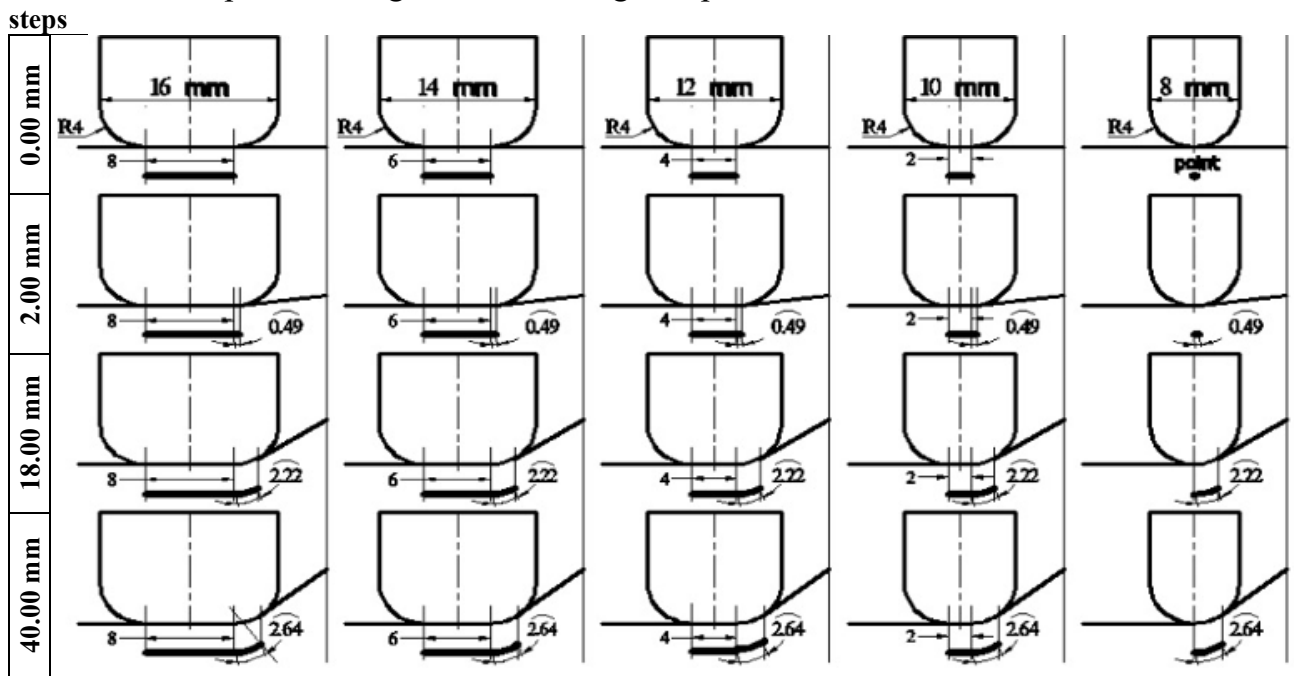

Fig. 5. Forming tool profile movement and a comparing of contact areas of spherical and flat.

The contact behaviour of each forming tool profile (simulation and Auto CAD models) shows differences, as illustrated Figs. 5 and 6 . The regions are defined depending on the contact state (forming tool surface - deformed blank surface), the simulation prediction shows four regions (far open, near contact, sliding and sticking), with different shapes and areas according to the deformation depth (Fig. 6).

Far open contact occurs between the flat region of the flat forming tool, which indicates small contact area. It also indicates the fact that the real contact only occurs at the forming tool edge contour, while two factors have impact on it: revolving speed and forming tool active diameter.

In case of the spherical forming tool, springback has a great impact, resulting in a larger contact area, higher friction and plastic region, where sticking also occurs.

Based on the contact statuses for successive depths $(0.2,10,20,30$ and $40 \mathrm{~mm})$ shown in Fig. 6, the following remarks can be made:

a. The contact has higher effects when the area is increased, and when depth increases

b. Sticking region increases and is transferred around the forming tool when depth of deformation increases, raising the probability of fracture, notably in the case of spherical forming tool, due to recurring deformation in wider areas. 


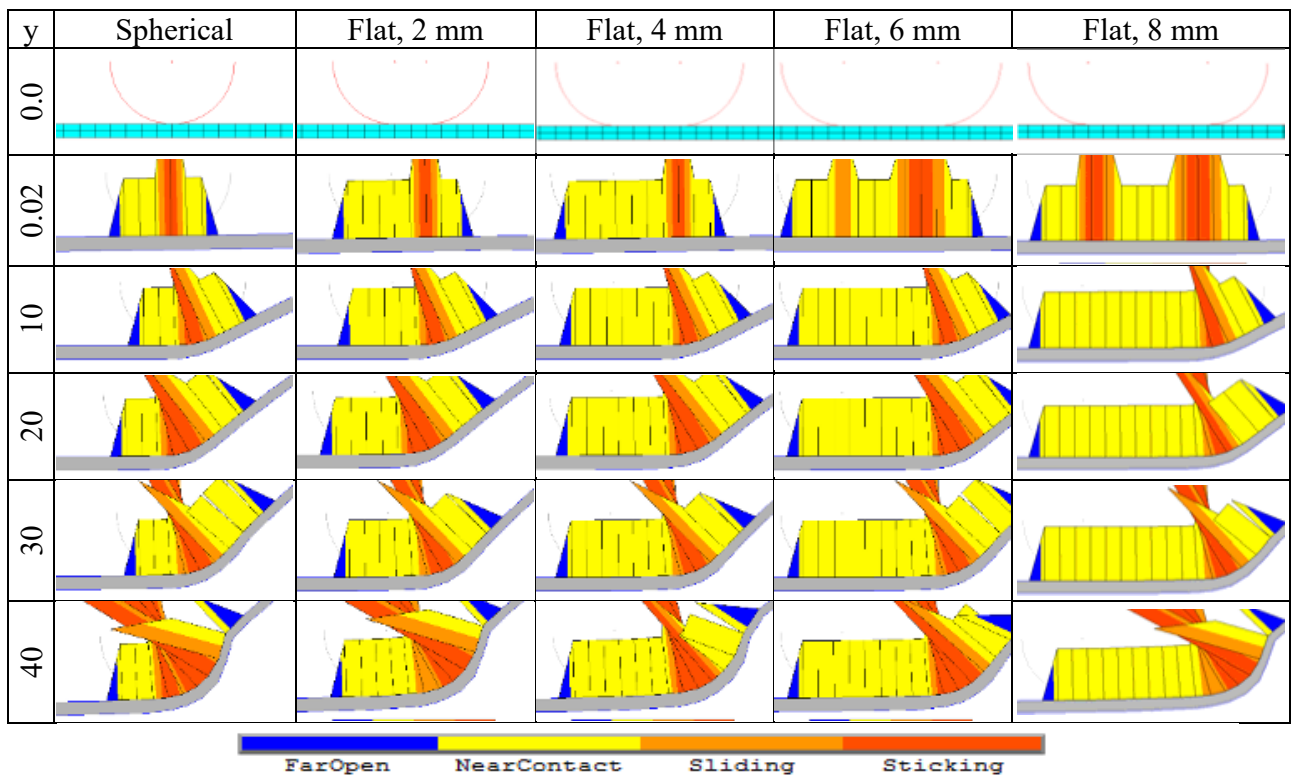

Fig. 6. Forming tool profile structure and contact status of flat forming tool profiles.

The stages of the deformation process and the forming tool strokes from the FEM simulation are presented in Fig. 7. The evaluation shows the results of the forming stages:

a. The end shape of the product has the same shape as the forming tool.

b. The final predicted shape of the spherical profile tool was quite different (Fig. 5).

c. Springabck is concentrated around the edges of the forming tool edge, at end stroke.

The thickness distribution along the section of the deformed shape section was evaluated at 2, 20 and $40 \mathrm{~mm}$ depths, as shown in Fig. 7. Thickness is constant at $2 \mathrm{~mm}$ and $20 \mathrm{~mm}$ depths. The changes in thickness occur at 40 to $50 \mathrm{~mm}$ distance from the product center, at 40 $\mathrm{mm}$ depth, around the edge of the forming tool, at final stroke. This phenomenon has no significant effect in case of the flat forming tool shape, even if the area is increased.
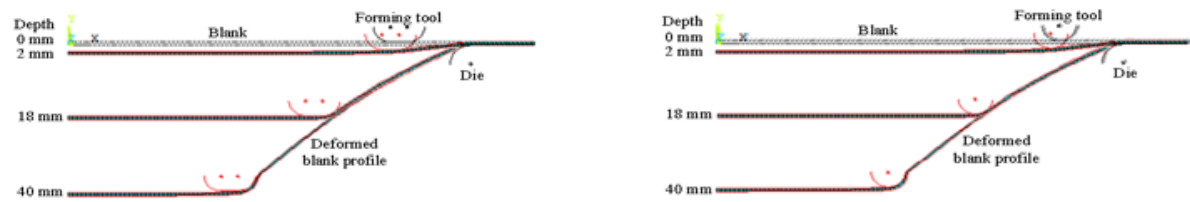

Fig. 7. Forming tool movement and product profiles and thickness distributions steps of Spherical and Flat.

The thickness distribution is influenced by the forming tool profile with radius from 2 to 6 $\mathrm{mm}$ is presented in Fig 8. The analysis is performed for a $40 \mathrm{~mm}$ forming tool stroke.

The highest thinning occurred at $40 \mathrm{~mm}$ depth, at $45 \mathrm{~mm}$ to $50 \mathrm{~mm}$ from the product center, in case of all products. Severe metal bending is occurring in case of the spherical forming tool lead to maximum values for thinning, which enables the formation of neck. At this point, product failure is clearly indicated. Thickness distribution varies according to forming tool changes, only in the case of the forming tool edge profile.

The edge of the forming tool has an obvious effect detected along the section of the product, even in the areas which have not been in direct contact (from $0 \mathrm{~mm}$ to $85 \mathrm{~mm}$ from the product center), as is presented in Fig. 8-a. Another observation is that between $45 \mathrm{~mm}$ to $85 \mathrm{~mm}$ from the product center, the thickness distribution is improved when the tool radius is increased. Thickness is reduced in the area from 0 to $45 \mathrm{~mm}$ from the product center (end of stroke). 
Thickness distribution is not influenced by the flat forming tool area, from $0 \mathrm{~mm}$ to 110 $\mathrm{mm}$ from the product center. As shown in Fig. 8-b, the only exception is the last position of the forming tool, where an improvement can be noticed, but it is not incidental.
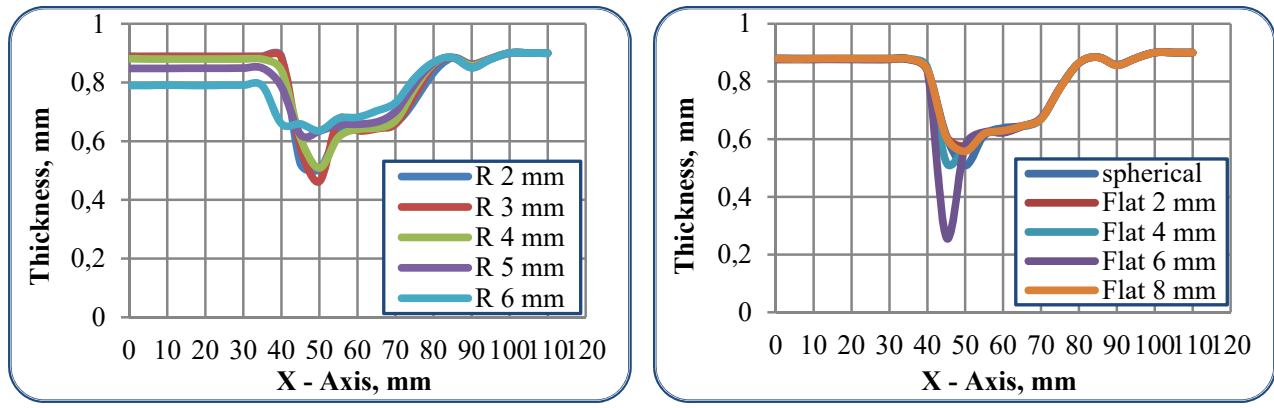

Fig. 8. Thickness distribution of spherical and flat forming tool.

\section{Conclusions}

The present work establishes the fact that any adjustment of the forming tool profile influences the SPIF formability based on surface shape of the interface. Product accuracy is not necessarily improved if the contact area is increased.

Defects appear as a consequence of the interaction between forming tool profile and the sheet thickness. As a result, the tool edge radius has impact on the thickness distribution.

There is no deformation effect of the flat forming tool area during the deformation steps except increasing the stiffness of the forming tool used. And the contact tool - blank only occurs at the edge of the tool. The wall and corner fold appear around the forming tool as a result of modifications in the flat forming tool edge.

Using 2D simulation model with high number of boundary conditions is easier, and the evaluation of contact statues is easier and quicker indication.

\section{References}

1. R. P. Singh, G. Goyal, Int. J. Eng. Research and Applications (IJERA), pp. 33-37, (2014).

2. M. Bambach , M. Cannamela , M. Azaouzi , G. Hirt and J. L. Batoz, Adv. Meth. Mate. Form, pp. 233-250, (2007).

3. R. Crina, Vasile Alecsandri Uni. of Bacau, Romania, J. Eng. Stud. Res., 16, 4, pp. 33-39, (2010).

4. G. Hussain, N. Hayat, G. Lin, J. Mech. Sci. and Tech., 26, 8, pp. 2337-2345, (2012).

5. M. A. Dittrich, T. G. Gutowski, J. Cao, J. T. Roth, J. Prod. Eng., 6, 2, pp. 169-177, (2012).

6. R. Benmessaoud, Int. J. Adv. Res. Comp. Sci. and Soft. Eng., 4, 5, pp. 1035-1044, (2014).

7. M. Ham, J. Jeswiet, CIRP Annals - Manufacturing Technology, 55, 1, pp. 241-244, (2006).

8. G. Hussain, L. Gao, N. Hayat, Int. J. Adv. Manuf. Tech., 46, 5-8, pp. 543-549, (2010).

9. M. B. Silva, P. S. Nielsen, N. Bay, Int. J. Adv. Manuf. Technol., 56, 9-12, pp. 893-903, (2011).

10. P. Eyckens, B. Belkassem, C. Henrard, Int. J. Mater. Form., 4, 1, pp. 55-71, (2011).

11. T. A. Marques, M. B. Silva, P. A. F. Martins, Int. J. Adv. Manuf. Tech., 60, 1-4, 75-86, (2012).

12. X. Ziran, L. Gao, G. Hussain, Int. J. Adv. Manuf. Tech., 46, 9-12, pp. 1113-1118, (2010).

13. M. Fiorotto, M. Sorgente, G. Lucchetta, Int. J. Mater. Form., 3, 1, pp. 951-954, (2010).

14. A. K. Behera, J. Verbert, J. R. Duflou, Computer-Aided Design, 45, 3, pp. 575-590, (2013).

15. C. F. Guzmán, J. Gu, J. Duflou, Int. J. Solids and Struct., 49, 25, pp. 3594-3604, (2012).

16. B. T. Araghi, G. L. Manco, M. Bambach, CIRP Annals-Manuf. Tech., 58, 1, pp. 225-228, (2009).

17. C. Robert, A. Delameziere, J. Mate. Pro. Tech., 212, 5, pp. 1123-1131, (2012). 